
$\angle$ Research Square
Preprints are preliminary reports that have not undergone peer review.
They should not be considered conclusive, used to inform clinical practice, or referenced by the media as validated information.

\title{
The Analgesic Comparison of Supraclavicular and Interscalene Brachial Plexus Block for Shoulder Arthroscopy: A Meta-Analysis of Randomized Controlled Trials
}

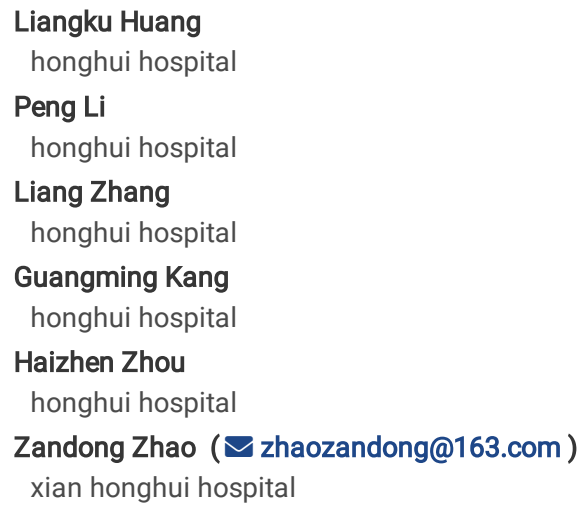




\section{Abstract \\ Introduction:}

The analgesic comparison of supraclavicular versus interscalene brachial plexus block (SCBB versus ISBB) for pain management of shoulder arthroscopy remains controversial. We conduct a systematic review and meta-analysis to explore the influence of SCBB versus ISBB on the postoperative pain intensity of shoulder arthroscopy.

\section{Methods}

We have searched PubMed, EMbase, Web of science, EBSCO, and Cochrane library databases through March 2021 for randomized controlled trials (RCTs) assessing the effect of SCBB versus ISBB on pain control of shoulder arthroscopy. This meta-analysis is performed using the random-effect model.

\section{Results}

Six RCTs are included in the meta-analysis. Overall, compared with ISBB for shoulder arthroscopy, SCBB leads to similar pain scores at $24 \mathrm{~h}$ (SMD $=0.07 ; 95 \%$ $\mathrm{Cl}=-0.14$ to $0.28 ; \mathrm{P}=0.52)$ and additional analgesic requirement $(\mathrm{SMD}=-0.22 ; 95 \% \mathrm{Cl}=-0.52$ to $0.09 ; \mathrm{P}=0.16)$, but results in increased onset time of block (SMD $=1.77 ; 95 \% \mathrm{Cl}=0.21$ to $3.34 ; \mathrm{P}=0.25)$, decreased incidence of horner's syndrome $(\mathrm{OR}=0.25 ; 95 \% \mathrm{Cl}=0.10$ to $0.64 ; \mathrm{P}=0.003)$ and adverse events $(\mathrm{OR}=0.25$; $95 \% \mathrm{Cl}=0.11$ to $0.58 ; \mathrm{P}=0.001)$.

\section{Conclusions}

SCBB demonstrated comparable pain control after shoulder arthroscopy compared to ISBB, with lower incidence of adverse events.

\section{Introduction}

The number of patients requiring shoulder arthroscopy has been increasing annually [1,2]. Significant postoperative pain is a main concern after shoulder arthroscopy and effective analgesia is required for this successful day-case surgery $[3,4]$. This pain is mainly derived from insertion of arthroscopic instruments into the joint, soft tissue dissection and distention [5-9]. Postoperative pain seriously affects patients' early mobilization and rehabilitation [1012]. Although interscalene brachial plexus block (ISBB) is widely accepted as the most effective analgesic technique for this surgery, it frequently induces phrenic nerve block even with the use of ultrasound and low volumes of local anaesthetic [13-16].

The alternatives to ISBB should be developed to decrease the related adverse events [16]. Supraclavicular brachial plexus block (SCBB) was reported to have the potential in decreasing the risk of adverse events, particularly when guided by ultrasound $[17,18]$. Previous studies compared the analgesic efficacy of SCBB with ISBB for ambulatory shoulder surgery, and the results revealed comparable efficacy of pain control between SCBB and ISBB [19]. In addition, many studies showed that SCBB is a safe technique in terms of respiratory complications [20-22].

Recently, several studies have explored the analgesic efficacy of SCBB with ISBB for the pain management of shoulder arthroscopy, but the results are conflicting $[1,23,24]$. With accumulating evidence, we therefore perform a systematic review and meta-analysis of RCTs to explore the efficacy of SCBB versus ISBB in patients with shoulder arthroscopy.

\section{Materials And Methods}

Ethical approval and patient consent are not required because this is a systematic review and meta-analysis of previously published studies. The systematic review and meta-analysis are conducted and reported in adherence to PRISMA (Preferred Reporting Items for Systematic Reviews and Meta-Analyses) [25, 26].

\section{Search strategy and study selection}

Two investigators have independently searched the following databases (inception to March 2021): PubMed, EMbase, Web of science, EBSCO, and Cochrane library databases. The electronic search strategy is conducted using the following keywords: supraclavicular, and interscalene, and brachial plexus block, and arthroscopy, and shoulder. We also check the reference lists of the screened full-text studies to identify other potentially eligible trials.

The inclusive selection criteria are as follows: (i) patients undergoing shoulder arthroscopy; (ii) intervention treatments are SCBB versus ISBB:; (iii) study design is RCT.

\section{Data extraction and outcome measures}

We have extracted the following information: author, number of patients, age, female, body weight, duration of surgery and detail methods in each group etc. Data have been extracted independently by two investigators, and discrepancies are resolved by consensus. We also contact the corresponding author to obtain the data when necessary.

The primary outcome are pain scores at $24 \mathrm{~h}$. Secondary outcomes include additional analgesic requirement, onset time of block, horner's syndrome and adverse events. 


\section{Quality assessment in individual studies}

Methodological quality of the included studies is independently evaluated using the modified Jadad scale [27]. There are 3 items for Jadad scale: randomization (0-2 points), blinding (0-2 points), dropouts and withdrawals (0-1 points). The score of Jadad Scale varies from 0 to 5 points. An article with Jadad score $\leq 2$ is considered to be of low quality. If the Jadad score $\geq 3$, the study is thought to be of high quality [28].

\section{Statistical analysis}

We estimate the standard mean difference (SMD) with 95\% confidence interval (Cl) for continuous outcomes (pain scores at $24 \mathrm{~h}$, additional analgesic requirement, and onset time of block) and odd ratios (ORs) with 95\% Cls for dichotomous outcomes (horner's syndrome and adverse events). The randomeffects model is used regardless of heterogeneity. Heterogeneity is reported using the $\mathrm{I}^{2}$ statistic, and $\mathrm{I}^{2}>50 \%$ indicates significant heterogeneity [26, 29] Whenever significant heterogeneity is present, we search for potential sources of heterogeneity via omitting one study in turn for the meta-analysis or performing subgroup analysis. All statistical analyses are performed using Review Manager Version 5.3 (The Cochrane Collaboration, Software Update, Oxford, UK).

\section{Results}

\section{Literature search, study characteristics and quality assessment}

A detailed flowchart of the search and selection results is shown in Figure 1. 102 potentially relevant articles are identified initially. Finally, six RCTs that meet our inclusion criteria are included in the meta-analysis [1, 23, 24, 30-32].

The baseline characteristics of the six eligible RCTs in the meta-analysis are summarized in Table 1 . The six studies are published between 2015 and 2019 , and sample sizes range from 44 to 126 . The local analgesics of SCBB or ISBB include bupivacaine, clonidine, ropivacaine and mepivacaine.

Among the six studies included here, four studies report pain scores at $24 \mathrm{~h}[1,23,24,31]$, five studies report additional analgesic requirement [1, 23, 24, 30, $31]$, two studies report onset time of block [23,30], five studies report horner's syndrome [23, 24, 30-32] and four studies report adverse events[1, 23, 30, 32]. Jadad scores of the six included studies vary from 3 to 5 , and all three studies are considered to be high-quality ones according to quality assessment.

\section{Primary outcome: pain scores at $24 \mathrm{~h}$}

This outcome data is analyzed with the random-effects model, and compared to ISBB for shoulder arthroscopy, SCBB results in similar pain scores at $24 \mathrm{~h}$ $(\mathrm{SMD}=-0.25 ; 95 \% \mathrm{Cl}=-0.79$ to $0.30 ; \mathrm{P}=0.37)$ with significant heterogeneity among the studies $\left(\mathrm{I}^{2}=86 \%\right.$, heterogeneity $\left.\mathrm{P}<0.00001\right)($ Figure 2$)$.

\section{Sensitivity analysis}

Significant heterogeneity is observed among the included studies for the primary outcome, so we do not perform sensitivity analysis via omitting one study in turn to detect the heterogeneity. As shown in Figure 2, the study conducted by Karaman shows the results that are almost out of range of the others and probably contributed to the heterogeneity [23]. After excluding this study, the results suggested that SCBB and ISBB are still associated with comparable pain scores at $24 \mathrm{~h}$ for shoulder arthroscopy $(\mathrm{SMD}=0.07 ; 95 \% \mathrm{Cl}=-0.14$ to $0.28 ; \mathrm{P}=0.52)$, and no heterogeneity remained $\left(\mathrm{I}^{2}=0.60, \mathrm{P}=0.58\right)$.

\section{Secondary outcomes}

In comparison with ISBB for shoulder arthroscopy, SCBB exhibits similar additional analgesic requirement (SMD=-0.22; $95 \% \mathrm{Cl}=-0.52$ to $0.09 ; \mathrm{P}=0.16$; Figure 3), but is associated increased onset time of block ( $\mathrm{SMD}=1.77 ; 95 \% \mathrm{Cl}=0.21$ to $3.34 ; \mathrm{P}=0.25$; Figure 4$)$, decreased incidence of horner's syndrome (OR=0.25; $95 \%$ $\mathrm{Cl}=0.10$ to $0.64 ; \mathrm{P}=0.003$; Figure 5$)$ and adverse events $(\mathrm{OR}=0.25 ; 95 \% \mathrm{Cl}=0.11$ to $0.58 ; \mathrm{P}=0.001$; Figure 6$)$.

\section{Discussion}

Many methods have been developed to control postoperative pain after arthroscopic shoulder surgery, and they include subacromial/intra-articular infiltration of local anesthetic, suprascapular and/or axillary nerve block, and interscalene block [33,34]. Especially, nerve block has become an important approach supplemental to multimodal approach which is widely applied to improve analgesia and reduce the opioid-related adverse effect [35]. ISBB can provide a blockade at the C5-C6 root level after arthroscopic shoulder surgery, but may result in some serious complications $[4,36]$. Numerous alternative techniques have been investigated, but hardly achieve equivalent analgesic methods compared with ISBB [3, 4].

US-guided anterior approach to the suprascapular nerve demonstrated that this nerve was located at an 8-mm (interquartile range, 6 to $9 \mathrm{~mm}$ ) median distance to the supraclavicular brachial plexus in cadavers. 20 A prospective study documented that SCBB may achieve as equal efficacy as ISBB for shoulder arthroscopy [19]. Our meta-analysis confirms that SCBB and ISBB show the comparable analgesic efficacy for arthroscopic shoulder surgery, as evidenced by the similar pain scores at $24 \mathrm{~h}$ and additional analgesic requirement between two groups. However, SCBB may be associated with relatively longer onset time of block than ISBB based on the results of our meta-analysis. The quality of recovery of the patients was reported to be satisfactory with these two techniques [23].

Horner's syndrome may occur and result from the paralysis of the ipsilateral sympathetic cervical chain by the local anesthetic, such as the procedure of ISBB and SCBB. 29,30 Previous studies compared the incidence of Horner's syndrome between ISBB and SCBB, and its incidence may be higher in ISBB than that in SCBB $[32,37]$. The results of our meta-analysis concluded that SCBB was associated with lower incidence of Horner's syndrome compared to ISBB after 
shoulder arthroscopy. In addition, the adverse events were still found to be lower after SCBB than those in ISBB. Regarding the sensitivity analysis, Significant heterogeneity is observed for the primary outcome. After excluding this study conducted by Karaman with $0.25 \%$ bupivacaine [23], no heterogeneity remains. SCBB and ISBB still have comparable pain scores at $24 \mathrm{~h}$ for shoulder arthroscopy. These indicate that $0.25 \%$ bupivacaine through SCBB may produce better analgesic efficacy than that through ISBB.

This meta-analysis has several limitations. Firstly, our analysis is based on six RCTs, and three of them have a relatively small sample size ( $\mathrm{n}<100$ ). Overestimation of the treatment effect is more likely in smaller trials compared with larger samples. Next, although there is significant heterogeneity, which may be caused by different doses, concentration and methods of analgesics. Finally, it is not feasible to perform the meta-analysis of some important index such as discharge time and time to first analgesic requirement based on current RCTs.

\section{Conclusions}

SCBB is recommended for shoulder arthroscopy because it can obtain the comparable analgesic efficacy than ISBB, especially with lower incidence of adverse events.

\section{Abbreviations}

randomized controlled trials: RCTs

mean differences: MDs

confidence intervals: Cls

risk ratios: RRs

\section{Declarations}

\section{Ethical Approval and Consent to participate}

Not applicable.

\section{Consent for publication}

Not applicable.

\section{Availability of supporting data}

Not applicable.

\section{Competing interests}

The authors declare no conflict of interest.

\section{Funding}

Not applicable.

\section{Authors' contributions}

Liangku Huang, Peng Li conducted the design, study planning, data analysis and data interpretation. Liangku Huang, Peng Li, Haizhen Zhou and Zandong Zhao wrote and revised the article. All authors read and approved the final manuscript.

\section{Acknowledgements}

None.

\section{Authors' information}

Liangku Huang ${ }^{1 \#}$ MD, Peng Li" MD, Liang Zhang ${ }^{3}$ MD, Guangming Kang ${ }^{2}$ MD, Haizhen Zhou ${ }^{1}$ MD, Zandong Zhao ${ }^{3^{*}}$ MD $^{2}$

Liangku Huang: lovehlk2003@163.com, Peng Li: lipeng2008.go@163.com, Liang Zhang: glowthy@sina.com.cn, Guangming Kang: ylhskgm@163.com; Haizhen Zhou: haizhen317@163.com, Zandong Zhao: zhaozandong@163.com;

${ }^{1}$ Department of Orthopaedic Oncology, Xi'an Honghui Hospital, Xi'an Jiaotong University Health Science Center, Xi'an, Shaanxi, 710054, China;

${ }^{2}$ Department of Hand Surgery, Xi'an Honghui Hospital, Xi'an Jiaotong University Health Science Center, Xi'an, Shaanxi, 710054, China;

${ }^{3}$ Sports Medicine Center, Xi'an Honghui Hospital, Xi'an Jiaotong University Health Science Center, Xi'an, Shaanxi, 710054, China; 
\#The first two authors contributed equally to this study

*Corresponding author: Zandong Zhao. Email: zhaozandong@163.com, N0.218 Ziqiang Street,Nanguan District, Xi'an, Shaanxi, 710054, China;

Telephone: 0431-81136136;

Fax number: 0431-81136136;

Declaration of conflict of interest: None;

\section{References}

1. Cabaton J, Nové-Josserand L, Mercadal L, Vaudelin T. Analgesic efficacy of ultrasound-guided interscalene block vs. supraclavicular block for ambulatory arthroscopic rotator cuff repair: A randomised noninferiority study. Eur J Anaesthesiol. 2019;36(10):778-86.

2. Burkhart SS. Shoulder arthroscopy: a bridge from the past to the future. Journal of shoulder elbow surgery. 2020;29(8):e287-96.

3. Uquillas CA, Capogna BM, Rossy WH, Mahure SA, Rokito AS. Postoperative pain control after arthroscopic rotator cuff repair. Journal of shoulder elbow surgery. 2016;25(7):1204-13.

4. Fredrickson MJ, Krishnan S, Chen CY. Postoperative analgesia for shoulder surgery: a critical appraisal and review of current techniques. Anaesthesia. 2010;65(6):608-24.

5. Botser IB, Smith TW Jr, Nasser R, Domb BG. Open surgical dislocation versus arthroscopy for femoroacetabular impingement: a comparison of clinical outcomes. Arthroscopy: the journal of arthroscopic related surgery : official publication of the Arthroscopy Association of North America the International Arthroscopy Association. 2011;27(2):270-8.

6. 29162135Li C, Qu J. Efficacy of dexmedetomidine for pain management in knee arthroscopy: A systematic review and meta-analysis. Medicine. 2017;96(43):e7938.

7. Tepolt FA, Bido J, Burgess S, Micheli LJ, Kocher MS, Opioid Overprescription After Knee Arthroscopy and Related Surgery in Adolescents and Young Adults, Arthroscopy: the journal of arthroscopic \& related surgery : official publication of the Arthroscopy Association of North America and the International Arthroscopy Association (2018).

8. Tong D, Chung F. Postoperative pain control in ambulatory surgery. Surg Clin North Am. 1999;79(2):401-30.

9. Chen X, Mou X, He Z, Zhu Y. The effect of midazolam on pain control after knee arthroscopy: a systematic review and meta-analysis. J Orthop Surg Res. 2017;12(1):179.

10. Nicholson T, Maltenfort M, Getz C, Lazarus M, Williams G, Namdari S. Multimodal pain management protocol versus patient controlled narcotic analgesia for postoperative pain control after shoulder arthroplasty. Archives of Bone Joint Surgery. 2018;6(3):196.

11. Jung HS, Seo KH, Kang JH, Jeong J-Y, Kim Y-S, Han N-R. Optimal dose of perineural dexmedetomidine for interscalene brachial plexus block to control postoperative pain in patients undergoing arthroscopic shoulder surgery: a prospective, double-blind, randomized controlled study, Medicine 97(16) (2018).

12. Calvo E, Torres MD, Morcillo D, Leal V. Rotator cuff repair is more painful than other arthroscopic shoulder procedures. Arch Orthop Trauma Surg. 2019;139(5):669-74.

13. Ullah H, Samad K, Khan FA. Continuous interscalene brachial plexus block versus parenteral analgesia for postoperative pain relief after major shoulder surgery, The Cochrane database of systematic reviews 2014(2) (2014) Cd007080.

14. Warrender WJ, Syed UAM, Hammoud S, Emper W, Ciccotti MG, Abboud JA, Freedman KB. Pain Management After Outpatient Shoulder Arthroscopy: A Systematic Review of Randomized Controlled Trials. Am J Sports Med. 2017;45(7):1676-86.

15. Hortense A, Perez MV, Amaral JL, Oshiro AC, Rossetti HB. Interscalene brachial plexus block. Effects on pulmonary function. Revista brasileira de anestesiologia. 2010;60(2):130-7, $74-8$.

16. Stundner O, Meissnitzer M, Brummett CM, Moser S, Forstner R, Koköfer A, Danninger T, Gerner P, Kirchmair L, Fritsch G. Comparison of tissue distribution, phrenic nerve involvement, and epidural spread in standard- vs low-volume ultrasound-guided interscalene plexus block using contrast magnetic resonance imaging: a randomized, controlled trial. Br J Anaesth. 2016;116(3):405-12.

17. Renes SH, Spoormans HH, Gielen MJ, Rettig HC, van Geffen GJ. Hemidiaphragmatic paresis can be avoided in ultrasound-guided supraclavicular brachial plexus block. Regional anesthesia pain medicine. 2009;34(6):595-9.

18. Kim BG, Han JU, Song JH, Yang C, Lee BW, Baek JS. A comparison of ultrasound-guided interscalene and supraclavicular blocks for post-operative analgesia after shoulder surgery. Acta anaesthesiologica Scandinavica. 2017;61(4):427-35.

19. Liu SS, Gordon MA, Shaw PM, Wilfred S, Shetty T, Yadeau JT. A prospective clinical registry of ultrasound-guided regional anesthesia for ambulatory shoulder surgery. Anesthesia analgesia. 2010;111(3):617-23.

20. Koscielniak-Nielsen ZJ. Supraclavicular catheter may be an alternative to interscalene catheter in patients at risk for respiratory failure after major shoulder surgery. Regional anesthesia pain medicine. 2013;38(3):251.

21. King R, Mariano ER, Yajnik M, Kou A, Kim TE, Hunter OO, Howard SK, Mudumbai SC. Outcomes of Ambulatory Upper Extremity Surgery Patients Discharged Home with Perineural Catheters from a Veterans Health Administration Medical Center, Pain medicine (Malden. Mass). 2019;20(11):2256-62.

22. Abdallah FW, Johnson J, Chan V, Murgatroyd H, Ghafari M, Ami N, Jin R, Brull R. Intravenous dexamethasone and perineural dexamethasone similarly prolong the duration of analgesia after supraclavicular brachial plexus block: a randomized, triple-arm, double-blind, placebo-controlled trial. Regional

Page 5/9 
anesthesia pain medicine. 2015;40(2):125-32.

23. Karaman T, Karaman S, Aşçı M, Tapar H, Şahin A, Dogru S, Suren M. Comparison of Ultrasound-Guided Supraclavicular and Interscalene Brachial Plexus Blocks in Postoperative Pain Management After Arthroscopic Shoulder Surgery, Pain practice: the. official journal of World Institute of Pain. 2019;19(2):196-203.

24. Auyong DB, Hanson NA, Joseph RS, Schmidt BE, Slee AE, Yuan SC. Comparison of Anterior Suprascapular, Supraclavicular, and Interscalene Nerve Block Approaches for Major Outpatient Arthroscopic Shoulder Surgery: A Randomized, Double-blind, Noninferiority Trial. Anesthesiology. 2018;129(1):47-57.

25. Moher D, Liberati A, Tetzlaff J, Altman DG, Group P. Preferred reporting items for systematic reviews and meta-analyses: the PRISMA statement. J Clin Epidemiol. 2009;62(10):1006-12.

26. Zhao J, Huang W, Zhang S, Xu J, Xue W, He B, Zhang Y, Efficacy of Glutathione for Patients With Cystic Fibrosis: A Meta-analysis of RandomizedControlled Studies, American Journal of Rhinology \& Allergy (2019) 1945892419878315.

27. Jadad AR, Moore RA, Carroll D, Jenkinson C, Reynolds DJM, Gavaghan DJ, McQuay HJ. Assessing the quality of reports of randomized clinical trials: Is blinding necessary? Control Clin Trials. 1996;17(1):1-12.

28. Kjaergard LL, Villumsen J, Gluud C. Reported Methodologic Quality and Discrepancies between Large and Small Randomized Trials in Meta-Analyses. Ann Intern Med. 2001;135(11):982-9.

29. Higgins JP, Thompson SG. Quantifying heterogeneity in a meta-analysis. Statistics in medicine. 2002;21(11):1539-58.

30. Aliste J, Bravo D, Fernández D, Layera S, Finlayson RJ, Tran DQ. A Randomized Comparison Between Interscalene and Small-Volume Supraclavicular Blocks for Arthroscopic Shoulder Surgery, Regional anesthesia and pain medicine 43(6) (2018) 590-595.

31. Wiesmann T, Feldmann C, Müller HH, Nentwig L, Beermann A, El-Zayat BF, Zoremba M, Wulf H, Steinfeldt T. Phrenic palsy and analgesic quality of continuous supraclavicular vs. interscalene plexus blocks after shoulder surgery. Acta anaesthesiologica Scandinavica. 2016;60(8):1142-51.

32. Ryu T, Kil BT, Kim JH. Comparison Between Ultrasound-Guided Supraclavicular and Interscalene Brachial Plexus Blocks in Patients Undergoing Arthroscopic Shoulder Surgery: A Prospective, Randomized, Parallel Study. Medicine. 2015;94(40):e1726.

33. Ciccone WJ, Busey II,TD, Weinstein DM, Walden DL, Elias JJ. Assessment of pain relief provided by interscalene regional block and infusion pump after arthroscopic shoulder surgery. Arthroscopy: The Journal of Arthroscopic Related Surgery. 2008;24(1):14-9.

34. Price D. The shoulder block: a new alternative to interscalene brachial plexus blockade for the control of postoperative shoulder pain. Anaesthesia intensive care. 2007;35(4):575-81.

35. Kehlet H, Dahl JB. The value of "multimodal" or "balanced analgesia" in postoperative pain treatment. Anesthesia Analgesia. 1993;77(5):1048-56.

36. Lenters TR, Davies J, Matsen FA 3. The types and severity of complications associated with interscalene brachial plexus block anesthesia: local and national evidence. Journal of shoulder elbow surgery. 2007;16(4):379-87. rd, ) ).

37. Auyong DB, Yuan SC, Choi DS, Pahang JA, Slee AE, Hanson NA. A Double-Blind Randomized Comparison of Continuous Interscalene, Supraclavicular, and Suprascapular Blocks for Total Shoulder Arthroplasty, Regional anesthesia and pain medicine 42(3) (2017) 302-309.

\section{Tables}


Table 1

Characteristics of included studies

\begin{tabular}{|c|c|c|c|c|c|c|c|c|c|c|c|c|}
\hline \multirow[t]{2}{*}{ No. } & \multirow[t]{2}{*}{ Author } & \multicolumn{6}{|c|}{ SCBB group } & \multicolumn{5}{|c|}{ ISBB group } \\
\hline & & Number & $\begin{array}{l}\text { Age } \\
\text { (years) }\end{array}$ & $\begin{array}{l}\text { Female } \\
\text { (n) }\end{array}$ & Weight (kg) & $\begin{array}{l}\text { Duration } \\
\text { of } \\
\text { surgery } \\
\text { (min) }\end{array}$ & Methods & Number & $\begin{array}{l}\text { Age } \\
\text { (years) }\end{array}$ & $\begin{array}{l}\text { Female } \\
\text { (n) }\end{array}$ & Weight (kg) & $\begin{array}{l}\text { Duri } \\
\text { of } \\
\text { surc } \\
\text { (mir }\end{array}$ \\
\hline 1 & $\begin{array}{l}\text { Karaman } \\
2019\end{array}$ & 29 & $\begin{array}{l}59 \\
(16.5)\end{array}$ & 14 & $73.07(8.80)$ & $140(30)$ & $\begin{array}{l}\text { SCBB with } 20 \\
\mathrm{~mL} \text { of } 0.25 \% \\
\text { bupivacaine }\end{array}$ & 31 & $52(20)$ & 20 & $72.56(8.56)$ & 120 \\
\hline 2 & $\begin{array}{l}\text { Cabaton } \\
2019\end{array}$ & 54 & $\begin{array}{l}57 \\
(50,65), \\
\text { median } \\
(I Q R)\end{array}$ & 21 & - & - & $\begin{array}{l}\text { SCBB with a } \\
\text { mixture of } 100 \\
\text { mg } \\
\text { levobupivacaine } \\
(20 \mathrm{ml}, 0.5 \%) \\
\text { and clonidine (1 } \\
\text { ug/kg) }\end{array}$ & 53 & $58(54,65)$ & 25 & - & - \\
\hline 3 & $\begin{array}{l}\text { Auyong } \\
2018\end{array}$ & 63 & $53 \pm 14$ & 24 & - & $88 \pm 25$ & $\begin{array}{l}\text { SCBB with } 15 \\
\text { ml, } 0.5 \% \\
\text { ropivacaine }\end{array}$ & 63 & $54 \pm 13$ & 25 & - & $90 \pm$ \\
\hline 4 & $\begin{array}{l}\text { Aliste } \\
2018\end{array}$ & 22 & $\begin{array}{l}58.0 \\
(14.1)\end{array}$ & 15 & - & $\begin{array}{l}75.0 \\
(32.4)\end{array}$ & $\begin{array}{l}\text { SCBB with } 20 \\
\mathrm{~mL} \text { of } \\
\text { levobupivacaine } \\
0.5 \% \text { and } \\
\text { epinephrine } 5 \\
\text { ug/mL }\end{array}$ & 22 & $58.4(8.7)$ & 10 & - & $\begin{array}{l}85.1 \\
(44 .\end{array}$ \\
\hline 5 & $\begin{array}{l}\text { Wiesmann } \\
2016\end{array}$ & 58 & $52.7(13)$ & 24 & $85.7(17)$ & - & $\begin{array}{l}\text { SCBB with an } \\
\text { initial bolus of } \\
10 \mathrm{ml} \text { of } \\
\text { ropivacaine } \\
0.2 \% \text { followed } \\
\text { by continuous } \\
\text { infusion of } \\
\text { ropivacaine } \\
0.2 \% \text { ( } 4 \mathrm{ml} \text { flow } \\
\text { rate, } 4 \text { ml bolus, } \\
30 \mathrm{~min} \text { lockout } \\
\text { time) }\end{array}$ & 56 & $53.0(13)$ & 22 & $86.1(17)$ & - \\
\hline 6 & Ryu 2015 & 46 & $\begin{array}{l}58.5 \\
(53.8- \\
64)\end{array}$ & 27 & 64.810 .8 & - & $\begin{array}{l}\text { SCBB with a } \\
\text { mixture } \\
\text { containing } 12.5 \\
\mathrm{~mL} \text { of } 1 \% \\
\text { mepivacaine } \\
\text { and } 12.5 \mathrm{~mL} \text { of } \\
0.75 \% \\
\text { ropivacaine }\end{array}$ & 47 & $\begin{array}{l}60(53- \\
65)\end{array}$ & 19 & 64.310 .0 & - \\
\hline
\end{tabular}

Supraclavicular brachial plexus block (SCBB), interscalene brachial plexus block (ISBB).

\section{Figures}




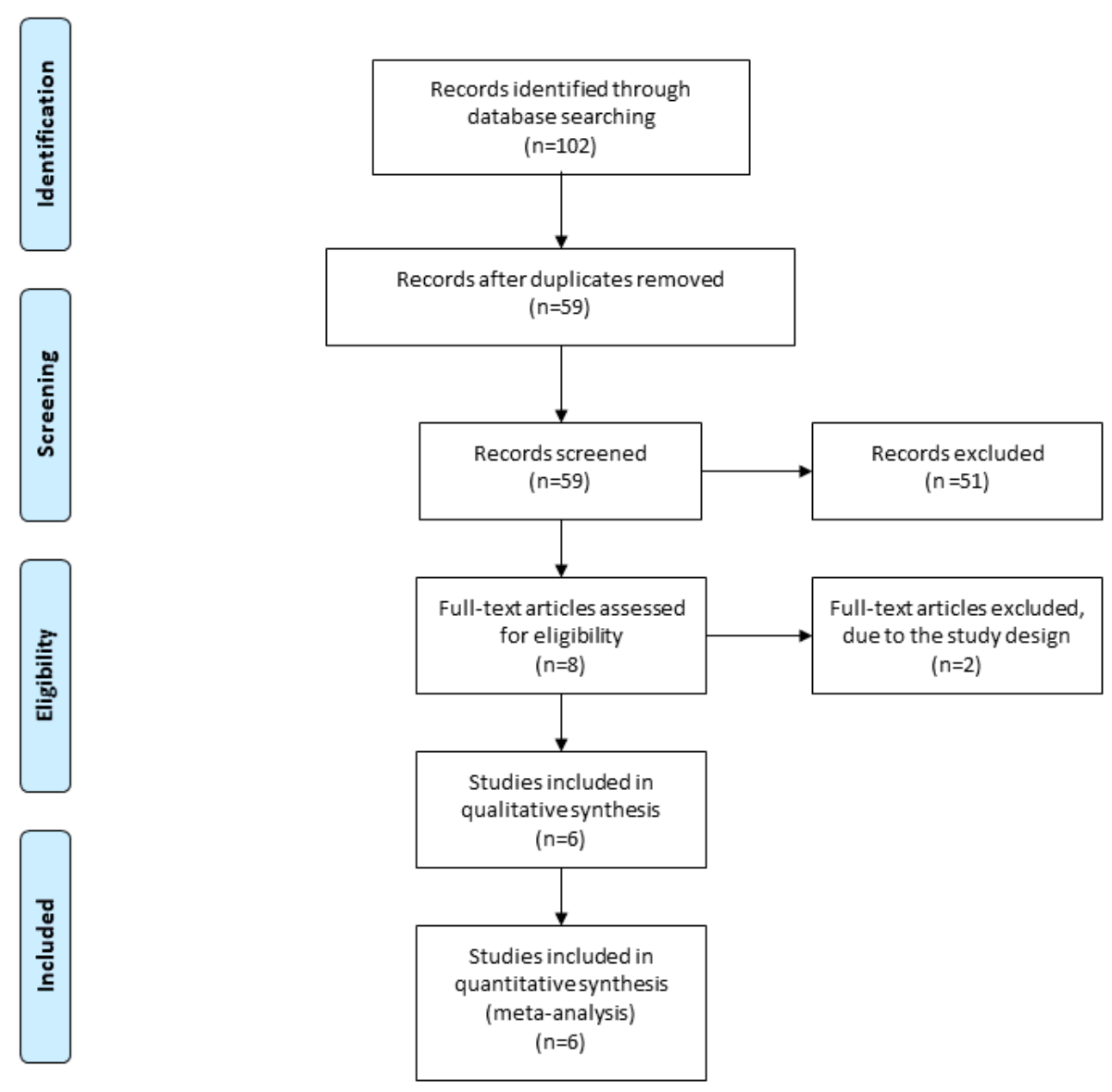

Figure 1

Flow diagram of study searching and selection process.

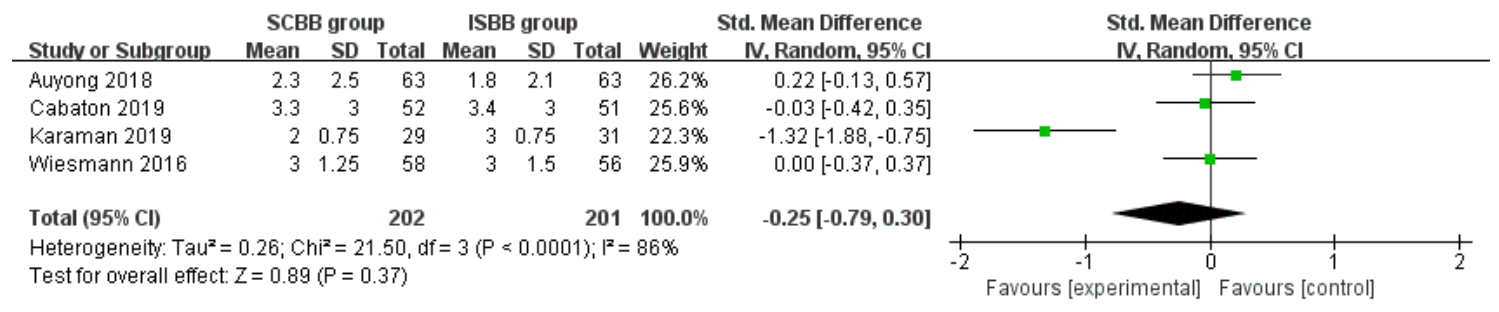

\section{Figure 2}

Forest plot for the meta-analysis of pain scores at $24 \mathrm{~h}$.

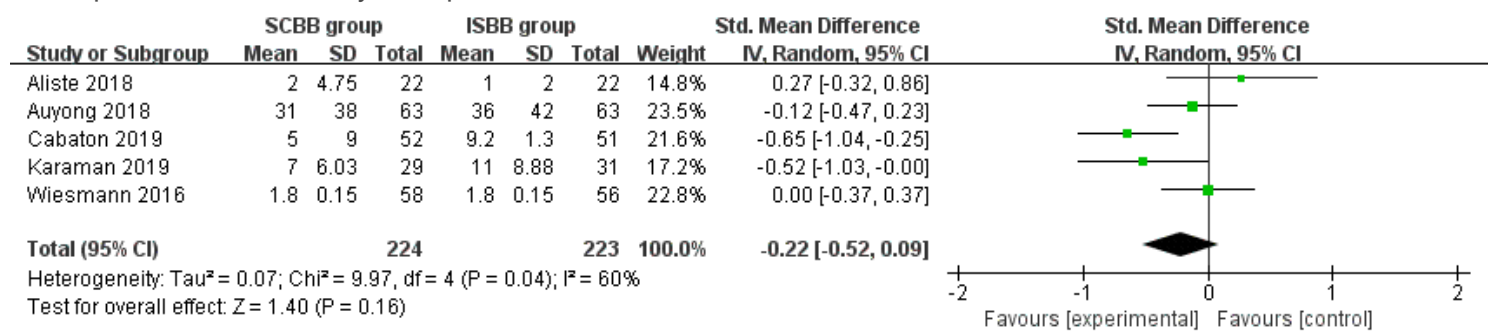

Figure 3

Forest plot for the meta-analysis of additional analgesic requirement. 


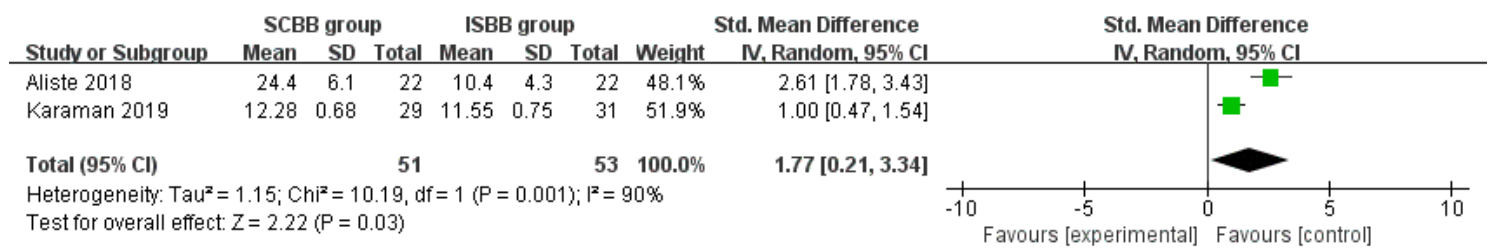

\section{Figure 4}

Forest plot for the meta-analysis of onset time of block.

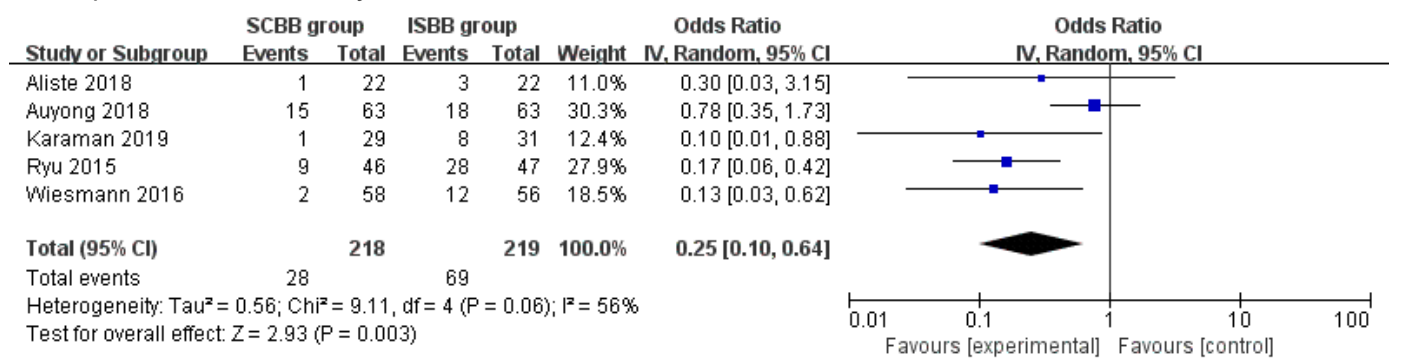

\section{Figure 5}

Forest plot for the meta-analysis of horner's syndrome.

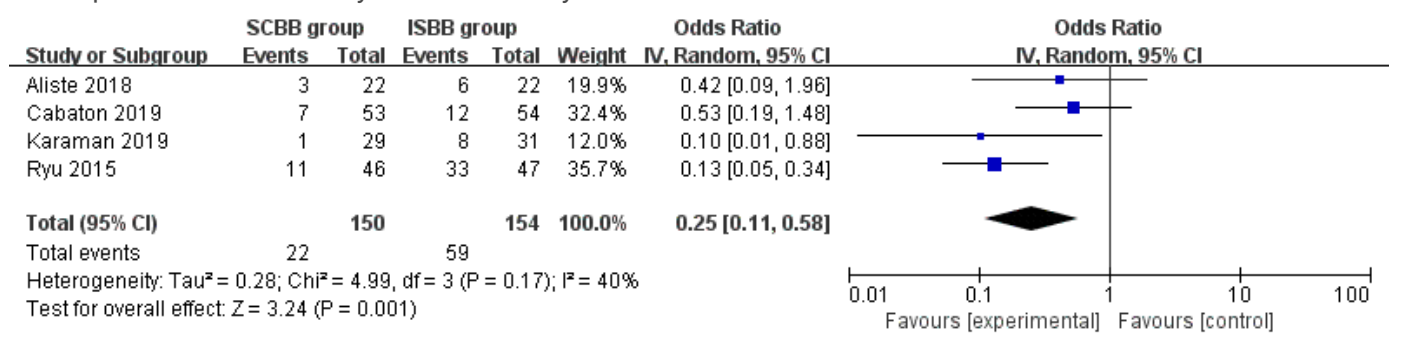

\section{Figure 6}

Forest plot for the meta-analysis of adverse events. 